\title{
Update Mammakarzinom 2019 Teil 1 - Implementierung der Ergebnisse neuer Studienkonzepte beim frühen Mammakarzinom in die klinische Praxis
}

\author{
Update Breast Cancer 2019 Part 1 - Implementation \\ of Study Results of Novel Study Designs in Clinical Practice \\ in Patients with Early Breast Cancer
}

\section{(ㄷ) (1) (오 $\ominus$}

Autoren

Andreas D. Hartkopf ${ }^{1}$, Volkmar Müller ${ }^{2}$, Achim Wöckel ${ }^{3}$, Michael P. Lux ${ }^{4}$, Wolfgang Janni ${ }^{5}$, Naiba Nabieva ${ }^{4}$,

Florin-Andrei Taran ${ }^{1}$, Johannes Ettl ${ }^{6}$, Diana Lüftner ${ }^{7}$, Erik Belleville ${ }^{8}$, Florian Schütz ${ }^{9}$, Peter A. Fasching ${ }^{4}$, Tanja N. Fehm $^{10}$, Hans-Christian Kolberg ${ }^{11}$, Friedrich Overkamp ${ }^{12}$, Andreas Schneeweiss ${ }^{13}$, Hans Tesch ${ }^{14}$

Institute

1 Department of Obstetrics and Gynecology, University of Tübingen, Tübingen

2 Department of Gynecology, Hamburg-Eppendorf

University Medical Center, Hamburg

3 Department of Gynecology and Obstetrics, University Hospital Würzburg, Würzburg

4 Erlangen University Hospital, Department of Gynecology and Obstetrics, Comprehensive Cancer Center Erlangen-

EMN, Friedrich-Alexander University Erlangen-Nuremberg, Erlangen

5 Department of Gynecology and Obstetrics, Ulm University Hospital, Ulm

6 Department of Obstetrics and Gynecology, Klinikum rechts der Isar, Technical University of Munich, Munich

7 Charité University Hospital, Campus Benjamin Franklin, Department of Hematology, Oncology and Tumour Immunology, Berlin

8 ClinSol GmbH \& Co. KG, Würzburg

9 Department of Obstetrics and Gynecology, University of Heidelberg, Heidelberg

10 Department of Gynecology and Obstetrics, University Hospital Düsseldorf, Düsseldorf

11 Department of Gynecology and Obstetrics, Marienhospital Bottrop, Bottrop

12 OncoConsult Hamburg GmbH, Hamburg

13 National Center for Tumor Diseases, Division Gynecologic Oncology, University Hospital Heidelberg, Heidelberg

14 Oncology Practice at Bethanien Hospital Frankfurt, Frankfurt

\section{Schlüsselwörter}

frühes Mammakarzinom, adjuvante Therapie, neoadjuvante Therapie, T-DM1, Katherine, Prävention

Key words

early breast cancer, adjuvant therapy, neoadjuvant therapy, T-DM1, Katherine, prevention

eingereicht 13.1.2019

akzeptiert 28.1.2019

Bibliografie

DOI https://doi.org/10.1055/a-0842-6614

Geburtsh Frauenheilk 2019; 79: 256-267 @ Georg Thieme

Verlag KG Stuttgart · New York I ISSN 0016-5751

Korrespondenzadresse

Peter A. Fasching, MD

Erlangen University Hospital, Department of Gynecology and Obstetrics, Comprehensive Cancer Center Erlangen EMN, Friedrich Alexander University of Erlangen-Nuremberg Universitätsstraße 21-23, 91054 Erlangen

peter.fasching@uk-erlangen.de

\section{ZUSAMMENFASSUNG}

In der Prävention und Behandlung des frühen Mammakarzinoms sind über die Jahre immer wieder kleine, aber bedeutsame Fortschritte gemacht worden. In der Prävention gewinnen die sogenannten Panel-Gen-Analysen immer mehr an Bedeutung, da das durch die getesteten Gene bedingte Risiko immer besser verstanden wird und somit Konzepte für die Integration in die Krankenversorgung erarbeitet werden können. In der adjuvanten Situation konnte die erste Studie in der sogenannten postneoadjuvanten Situation bei fehlender pathologischer Komplettremission nach Trastuzumab oder 
Pertuzumab + Trastuzumab eine deutliche Verbesserung der Prognose zeigen. Weitere Studien mit diesem postneoadjuvanten Therapiekonzept werden zurzeit noch durchgeführt. Die CDK4/6-Inhibitoren, die in der metastasierten Situation eine deutliche Verbesserung des progressionsfreien Überlebens gezeigt hatten, werden zurzeit in der adjuvanten Situation in großen Therapiestudien getestet. Diese und weitere neue Daten zur Behandlung oder Prävention des primären Mammakarzinoms werden in dieser Übersichtsarbeit vor dem Hintergrund aktueller Studien vorgestellt.

\section{ABSTRACT}

For many years, small but significant advancements have been made time and again in the prevention and treatment of early breast cancer. The so-called panel gene analyses are becoming more and more important in prevention, since the risk due to the tested genes is better understood and as a result, concepts for integration in health care can be developed. In the adjuvant situation, the first study in the so-called postneoadjuvant situation was able to demonstrate a clear improvement in the prognosis with an absent pathological complete remission following trastuzumab or pertuzumab + trastuzumab. Additional studies with this post-neoadjuvant therapeutic concept are still being conducted at present. The CDK4/6 inhibitors which had shown a significant improvement in progression-free survival in a metastatic situation are currently being tested in the adjuvant situation in large therapeutic studies. These and other new data for the treatment or prevention of primary breast cancer are presented in this review against the backdrop of current studies.

\section{Einführung}

Die Prognose des primären, frühen Mammakarzinoms hat sich in den letzten Jahrzehnten immer weiter verbessert. Dies zeigt sich sowohl in der Verbesserung des 5-Jahres-Überlebens als auch in der Steigerung der Raten pathologischer Komplettremissionen (pCR) im Rahmen von neoadjuvanten Therapiekonzepten [1,2]. Dies legt nahe, dass nicht nur eine Optimierung der lokalen Therapie oder der Früherkennung [3,4] die Prognose verbessert hat, sondern auch die systemische Therapie. Die Einführung neuer Substanzen und Therapieregimen konnte nach und nach die Therapie in der (neo)adjuvanten Situation verbessern [5-7]. Hierbei scheint die Wahl der Patientinnenpopulation eine immer wichtigere Rolle zu spielen. Vor einigen Jahren wurden z. B. sogenannte post-neoadjuvante Studien begonnen, welche die Patientinnen weiterbehandelten, die nach einer neoadjuvanten Therapie keine Komplettremission erreicht hatten. Diese Art von Studien scheinen insbesondere deswegen eine wichtige Rolle zu spielen, weil sie eine spezifische Resistenzpopulation untersuchen. Dieses Therapiekonzept, aber auch Aspekte der Prävention, operativen Behandlung, Radiotherapie und weiterer Behandlungsstrategien werden in dieser Übersichtsarbeit dargestellt.

\section{Prävention und Risikofaktoren}

Nach nunmehr 25 Jahren nach der Entdeckung von BRCA1 und BRCA2 haben sich die Techniken zur Genotypisierung deutlich weiterentwickelt, während die Kosten gesunken sind. Schon heute werden bei einer Testung für Risikogene in der Keimbahn nicht mehr nur BRCA1 und BRCA2 genotypisiert, sondern eine Reihe weiterer Gene, die ebenfalls einen Einfluss auf das Brustkrebsrisiko haben. Meistens handelt es sich bei diesen Genen um weitere Gene, die im Falle einer Mutation entweder auch mit einem ähnlich hohen Erkrankungsrisiko wie BRCA1 oder BRCA2 einhergehen, oder solche, die in ein mittleres Erkrankungsrisiko münden [8$10]$.

Verschiedene Arbeiten haben über die Mutationsfrequenzen oder Risiken im Vergleich zu gesunden Kontrollpersonen berichtet [11-17]. Eines der Gene, welches diskutiert wurde, entweder in die Hochrisikogruppe (ähnlich wie BRCA1 und BRCA2) oder in die Gruppe mit einem mittleren Erkrankungsrisiko eingeordnet zu werden, ist PALB2 [11,12]. Erste Arbeiten hatten das Lebenszeitrisiko zwischen 35 und $55 \%$ eingeschätzt $[11,18]$. Nun wurde eine weitere große Studie veröffentlicht, die ausgedehnte Panel-GenAnalysen an ca. 20000 Brustkrebsfällen und 20000 gesunden Kontrollpersonen analysiert hat [19]. Diese Studie beschreibt die relativen Risiken für $B R C A 1$ und $B R C A 2$ mit Werten von 7,9 und 6,7 und zeigt für PALB2 ein relatives Risiko von 4,8. Weitere mit statistischer Signifikanz identifizierten Gene waren CHEK2 und ATM mit relativen Risiken von 2,5 und 1,7. Wurden die Fälle auf die triple-negativen Patientinnen begrenzt, zeigten sich Odds Ratios von ca. 40 für $B R C A 1$, ca. 14 für PALB2 und ca. 9 für $B R C A 2$ [19]. In der klinischen Praxis sind Lebenszeitrisiken hilfreicher als relative Risiken. Die entsprechenden Lebenszeitrisiken wurden mit 50-55\% für BRCA1 und BRCA2 berechnet. PALB2 folgte mit etwas unter $35 \%$. CHEK2 und ATM lagen mit 25 und $15 \%$ darunter [19]. Diese Lebenszeitrisiken scheinen hoch genug zu sein, um individuelle risikoreduzierende Maßnahmen zu diskutieren, sind jedoch nicht die einzigen genetischen Faktoren, für die bekannt ist, dass sie das Brustkrebsrisiko erhöhen. Die hochgradig und mittelgradig penetranten Risikogene erklären ca. $20 \%$ des familiären Risikos für Brustkrebs, während niedrig penetrante, aber häufige genetische Varianten in über 170 Loci weitere $16 \%$ des familiären Brustkrebsrisikos erklären [8,20-27]. Um auch diese niedrig penetranten Risikovarianten eventuell für eine individuelle Risikobestimmung nutzbar zu machen, wurde bereits zu einem früheren Zeitpunkt mit 77 Genloci ein Risikoscore entwickelt [28]. Dieser wurde nun um weitere Risikogene ergänzt und mit 313 Genloci neu entwickelt. Frauen in der höchsten Perzentile hatten ein Lebenszeitrisiko von ca. 33\% ( $\bullet$ Abb. 1), was durchaus für eine individuelle Beratung von Belangen sein kann [29]. Für Frauen im Alter von um die 60 Jahre konnte ein 10-Jahres-Erkrankungsrisiko von über $10 \%$ errechnet werden [29]. Wichtig wie bei allen Risikoberechnungen ist die Erkennung von Frauen mit einem Risiko für ein Mammakarzinom mit einer schlechten Prognose. Hier zeigte sich, dass der polygenische Risikoscore insbesondere das Risiko für hormonrezeptorpositive Karzinome vorhersagte. Während das Lebenszeitrisiko für hormonrezeptorpositive Karzinome von 
über $30 \%$ berechnet werden konnte, lag das entsprechende Lebenszeitrisiko für hormonrezeptornegative Karzinome bei ca. 4\% [29]. Die Gene, die ein subtypspezifisches Risiko ausmachen, sind teilweise bekannt [15, 22, 30-39] und von besonderem Interesse für die Entwicklung von individualisierten präventiven Maßnahmen.

Die zusätzliche Kombination mit anderen Risikofaktoren könnte eine weitere Verbesserung der Risikoprädiktion mit sich bringen, da bekannt ist, dass nicht genetische Risikofaktoren subtypspezifische Effekte auf das Risiko haben [40] und der polygenische Risikoscore entweder mit anderen Risikofaktoren interagiert oder nicht genetische Risikofaktoren die Risikoprädiktion zusätzlich zum Risikoscore verbessern [41-43].

\section{Operative Therapie}

In diesem Jahr wurde von einem Experten-Panel eine Bedarfsanalyse publiziert, welche die Felder identifizierte, auf die im Bereich der Brustchirurgie in der nächsten Zukunft wissenschaftlich ein besonderer Fokus gelegt werden sollte. Die wichtigen Ziele der Weiterentwicklung sind in $>$ Tab. 1 dargestellt: eine Roadmap für

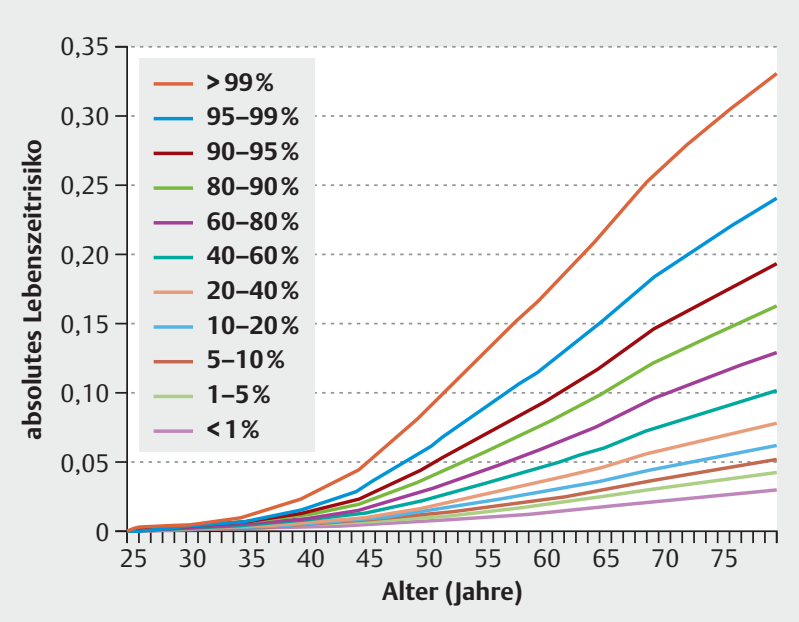

- Abb. 1 Kumulatives Lebenszeitrisiko für gesunde Frauen, in Abhängigkeit von einem Polygen-Risiko-Score mit 313 Genloci (aus [29]). Dargestellt sind die Perzentilen des Risiko-Scores und das davon abhängige Lebenszeitrisiko.

- Tab. 1 Wichtige Ziele zur Weiterentwicklung der Mammachirurgie (nach [44]).

Diagnose und Beurteilung
. Thematisierung von Überdiag-
nose und Überbehandlung,
insbesondere im Kontext des
Screenings
- Verständnis der Biologie,
Bedeutung und langfristigen
Outcomes von intermediären
(B3-)Läsionen und des dukta-
len Carcinoma in situ
" Verständnis der biologischen
Bedeutung und optimalen the-
rapeutischen Strategien bei
zusätzlichen Foci einer zuvor
subklinischen Erkrankung, die
mittels fortgeschrittener Bild-
gebungsverfahren festgestellt
wurden
- Ermittlung des besten Modells
für die symptomatische Be-
wertung, das eine schnelle, pa-
tientenzentrierte und kosten-
effektive Beurteilung ermög-
licht und dabei die diagnosti-
sche Genauigkeit wahrt
- Festlegung von Art und Zeit-
punkt des Stagings auf Fern-
metastasen und der besten
Rezidivüberwachung

neoadjuvante Therapie

- Verständnis, welche Patientinnen von einer neoadjuvanten Chemotherapie oder endokrinen Therapie am meisten profitieren, wie sich dieser Nutzen je nach biologischem Subtyp unterscheidet und welche Biomarker am besten geeignet sind, Therapieentscheidungen zu leiten (z. B. durch sog. Window-of-OpportunityStudies)

- Ermittlung der optimalen Therapiewahl und-abfolge

- Verständnis der langfristigen Outcomes einer neoadjuvanten endokrinen Therapie

- Ermittlung der optimalen Modalitäten (radiologisch und Biomarker) für die Überwachung des therapeutischen Ansprechens

- Raten der brustkonservierenden Operationen nach neoadjuvanter Behandlung optimieren

- Feststellen, ob bei Patientinnen, die eine pathologische Komplettremission (pathological complete response, pCR) erreichen, auf eine Operation sicher verzichtet werden kann, und mit welchen Bildgebungsverfahren oder Biopsiemethoden eine $\mathrm{PCR}$ zuverlässig vorhergesagt werden kann

- Verständnis des optimalen Managements der Axilla bei Patientinnen unter neoadjuvanter Therapie, insbesondere solchen mit Wechsel von einem positiven zu einem negativen Nodalstatus unter Therapie, sowie Verständnis der Rolle der SentinelLymphknoten-Biopsie nach Behandlung chirurgisches Management

- Entwicklung von Strategien zur Verminderung der Reexzisionsraten bei Patientinnen nach brustkonservierender Operation mittels fortgeschrittener Lokalisationstechniken und Methoden zur intraoperativen Randbeurteilung

- Verständnis der Rolle von Alternativen zur chirurgischen Exzision. Bewertung der klinischen und kostenbezogenen Effektivität der onkoplastischen und rekonstruktiven Chirurgie mittels standardisierter Messgrößen und des diesbezüglichen Einflusses von Patientenfaktoren und adjuvanten Therapien, vor allem adjuvanten Radiotherapien der Brustwand

- Robuste Evaluation innovativer Verfahren und Techniken mit geeigneten Methoden wie dem IDEAL-Framework sowie Verständigung der chirurgischen Fachwelt auf das Konzept „keine Innovation ohne Evaluation“

- Management der Axilla bei Patientinnen mit positiver Sentinel-Lymphknoten-Biopsie

\section{besondere Gruppen}

- Definition und Standardisierung der Indikationen für risikoreduzierende Chirurgie und Verständnis der langfristigen Outcomes bilateraler Mastektomien bei Hochrisikopatientinnen

- Definition und Standardisierung der Indikationen für kontralaterale Mastektomien bei Patientinnen mit vorheriger Krebserkrankung, um den Benefit zu optimieren und Schaden zu minimieren

- Vertieftes Verständnis von Brustkrebs und der unterschiedlichen Bedürfnisse von spezifischen Patientengruppen, darunter Patientinnen unter 40 Jahren, ältere Patientinnen, Männer sowie Patientinnen mit schwangerschaftsassoziiertem Mammakarzinom

- Weitere Untersuchung des Überlebens, einschließlich Optimierung der Nachsorge und Sekundärprävention, sowie der Rolle der Chirurgie bei der behandlungsassoziierten Morbidität, z. B. Lymphödem

- Verständnis der Rolle der Chirurgie bei metastasierter Erkrankung 
den Forschungsbedarf in der Brustchirurgie zum aktuellen Zeitpunkt [44]. Zu einigen der in dem Bericht aufgeworfenen Fragen gab es in diesem Jahr interessante Ergebnisse, auf denen die zukünftigen Forschungsansätze aufbauen können.

Die in den USA durchgeführte Young Women's Breast Cancer Study [45] schloss zwischen 2006 und 2016 insgesamt 1302 Frauen unter 40 Jahren mit einem invasiven Mammakarzinom ein, von denen 317 eine neoadjuvante Therapie erhielten. Prätherapeutisch wurden lediglich 85 Patientinnen (27\%) als Kandidatinnen für eine brusterhaltende Therapie eingeschätzt. Posttherapeutisch erhöhte sich diese Zahl auf 163 (51\%). Nur 80 dieser Patientinnen (49\%) entschieden sich für eine brusterhaltende Therapie, 83 (51\%) wählten die Mastektomie. Die beiden wichtigsten Gründe für eine Mastektomie waren Patientenpräferenz (46\%) und/ oder eine BRCA1/2- bzw. TP53-Mutation (37\%). Von den 75 Patientinnen (24\%), die eine pCR erreichten, erhielten 48 (64\%) eine Mastektomie, davon nur 21 (44\%) aus anatomischen Gründen (inflammatorisches Karzinom, extensive intraduktale Komponente etc.) [45]. Diese Daten zeigen, dass gerade bei jungen Patientinnen die Entscheidung für oder gegen eine Mastektomie nach neoadjuvanter Therapie oft eher aus persönlichen und risikoreduzierenden als aus streng onkologischen Gründen fällt [45]. Ob diese Ergebnisse auf andere Versorgungsstrukturen, wie z.B. in Deutschland, übertragbar sind, ist bislang noch nicht untersucht worden.

In diesem Zusammenhang ist auf die Ergebnisse zweier weiterer Studien mit jeweils weit über 500 Patientinnen hinzuweisen, die sich mit der Langzeitlebensqualität nach Brustkrebschirurgie auseinandergesetzt haben: die E5103-Studie [46], die alle Altersklassen eingeschlossen hatte, und eine weitere große Multicenterstudie, welche die Quality of Life (QoL) bei Patientinnen unter 40 betrachtet hatte [47]. In beiden Untersuchungen fanden die Autoren Hinweise, dass die Langzeitlebensqualität von der Radikalität des chirurgischen Ansatzes negativ beeinflusst wurde. Insbesondere in der Untersuchung, die Patientinnen unter 40 Jahren eingeschlossen hatte (Range 26-40, mittleres Alter 37 Jahre), waren das psychosoziale und sexuelle Wohlbefinden in der Gruppe der mastektomierten Patientinnen signifikant schlechter $[46,47]$. Aus anderen Studien ist bekannt, dass die Unzufriedenheit mit dem Ergebnis nach einer Mastektomie ohne Rekonstruktion über viele Jahre persistiert [48]. Sicher müssen solche Daten im Lichte moderner und weniger traumatisierender Rekonstruktionstechniken fortlaufend überprüft werden, sie sollten aber im Sinne des Informed Consent bei der präoperativen Beratung zur Sprache gebracht werden.

Zur Frage des Managements der Axilla nach neoadjuvanter Chemotherapie wurden in diesem Jahr mehrere translationale Analysen der SENTINA-Studie [49] vorgestellt. In einer Untersuchung wurde der posttherapeutische Befall axillärer Lymphknoten bei befallenen Sentinel-Lymphknoten vor neoadjuvanter Therapie analysiert. 71 von 318 Patientinnen (22,3\%) hatten nach neoadjuvanter Therapie noch befallene Lymphknoten, wobei Patientinnen mit einem positiven HER2-Status und einem negativen Axillastatus die höchsten pCR-Raten der Brust hatten [50]. Auch in einer weiteren Analyse, in der ein Nomogramm für die Vorhersage einer nodalen Konversion für Patientinnen mit prätherapeutisch befallenen Lymphknoten entwickelt wurde, war der stärkste prä- diktive Faktor die Tumorbiologie [51]. Diese Untersuchungen lassen aktuelle Konzepte vielversprechend erscheinen, in Studien bei Patientinnen mit einer aggressiven Tumorbiologie und pCR in der Brust bei posttherapeutisch klinisch unauffälligen Lymphknoten auf eine axilläre Chirurgie zu verzichten.

\section{Radiotherapie}

\section{Management bei positivem Lymphknotenbefall}

Die Sentinel-Lymphknoten-Biopsie (SNB) ist der Standard bei klinisch unauffälligen axillären Lymphknoten. Was soll man aber tun, wenn diese Lymphknoten tumorbefallen sind? Die ACOSOG0011Studie hat gezeigt, dass ein Verzicht auf eine weiterführende axilläre Lymphonodektomie (ALND) nicht zu einer erhöhten Rezidivrate führt, obwohl $23 \%$ der Patientinnen weitere befallene Lymphknoten aufweisen, die in situ verbleiben. Die Hauptkritiken an der Studie waren die geringe statistische Power (Abbruch wegen niedriger Rekrutierung) und die unklaren Bestrahlungsfelder an der Axilla [52].

Die Fragestellung der AMAROS-Studie $(n=1425)$ [53] war hier klarer definiert: bei einer positiven SNB bestrahlen (AxRT) oder operieren (ALND)? Nach 10 Jahren Follow-up zeigte sich insgesamt eine sehr geringe Lokalrezidivrate in beiden Armen, obwohl in dem operativen Arm bei 32,8\% der Patientinnen weitere Metastasen gefunden wurden. Die axilläre Rezidivrate betrug im AxRT-Arm 1,82\% und im ALND-Arm 0,93\% (HR 1,71; 95\%-KI: $0,67-4,39, p=0,365)$. Auch im DFS bestand kein Unterschied (HR 1,19; 95\%-KI: 0,97-1,45). Die behandlungsbedürftige Lymphödemrate war in dem ALND-Arm jedoch signifikant höher. 82\% der Patientinnen erhielten eine brusterhaltende Operation, $17 \%$ eine Ablatio mammae, sodass die Ergebnisse für beide Kollektive repräsentativ erscheinen bei allerdings sehr niedriger Eventrate. Fazit: Bei klinisch unauffälliger Axilla und trotzdem befallenen Sentinel-Lymphknoten erscheint eine weitere Operation nicht sinnvoll. Ob eine ausgedehnte (AMAROS) oder eine tangentiale (ACOSOG0011) Bestrahlung durchgeführt werden sollte, kann bisher nicht beantwortet werden [53].

\section{Teilbrustbestrahlung}

Auch in der Strahlentherapie ist die Deeskalation eine wichtige Strategie zur Reduktion therapiebedingter Morbidität und/oder der Behandlungsdauer. Die Teilbrustbestrahlung mittels interstitieller Brachytherapie, dreidimensionaler konformaler, externer Bestrahlung oder intraoperativer Bestrahlung (z. B. Intrabeam ${ }^{\circledR}$ ) könnte hierzu einen Beitrag leisten. Im Rahmen der randomisierten Phase-III-Studie NSABP B-39, die insgesamt 4216 Patientinnen mit primärem Mammakarzinom im Stadium I-III einschloss, wurde die Nichtunterlegenheit der Teilbrustbestrahlung gegenüber der konventionellen Gesamtbrustbestrahlung untersucht [54]. Alle Formen der Teilbrustbestrahlung waren erlaubt. Als primärer Endpunkt der Studie wurde die ipsilaterale Rezidivrate ausgewählt. Das mediane Follow-up betrug 10,2 Jahre. Die Nichtunterlegenheit konnte leider nicht gezeigt werden, wenngleich die 10-Jahres-Rezidivrate bei der Teilbrustbestrahlung nur um $0,7 \%$ höher lag (4,6 vs. 3,9\%). Zwar war das rezidivfreie Intervall bei der Teilbrustbestrahlung signifikant kürzer (rezidivfreies 10 - 
Jahres-Intervall 91,8 vs. 93,4\%), allerdings zeigte sich kein Unterschied beim metastasen- und krankheitsfreien Überleben bzw. Gesamtüberleben. Die Toxizitätsraten Grad 3-5 unterschieden sich nicht wesentlich. Somit kann für die Low-Risk-Patientinnen die Teilbrustbestrahlung aufgrund des nur geringfügig erhöhten Rezidivrisikos gegenüber der Gesamtbrustbestrahlung eine Option darstellen.

\section{Bestrahlung der Lymphabflusswege}

Die Indikation zur Bestrahlung des Lymphabflussgebiets (LAG) ist basierend auf den aktuellen Leitlinien und Therapieempfehlungen der Befall von mehr als 3 Lymphknoten (LK) unabhängig von der Tumorgröße sowie Hochrisikokonstellationen (1-3 LKs befallen, G2-3, ER/PR negativ) [55-57]. Eine aktuelle Metaanalyse, die insgesamt Daten von 13500 Patientinnen aus 14 Studien einschloss, bestätigte dieses Vorgehen [58]. Während frühere Studien aus den Jahren 1961-1978 mit einer gering verbesserten Brustkrebsmortalität $(-0,5 \%)$, aber erhöhten Gesamtmortalität einhergingen, zeigte sich in den jüngeren Studien ab den Jahren 1989 eine deutlich reduzierte Brustkrebs- und Gesamtmortalität (-2,8 bzw. $-2,9 \%)$. Dies ist am ehesten auf die Präzisionsstrahlentherapie zurückzuführen, welche die kardiale Strahlenbelastung (unter 8 Gy) minimiert. In der Subgruppenauswertung profitierten besonders Patientinnen mit mehr als 3 befallenen LKs von einer Bestrahlung des LAG. Die Metaanalyse bestätigt somit das aktuell empfohlene Vorgehen.

\section{Therapie des primären triple-negativen Mammakarzinoms}

Die Behandlung des triple-negativen Mammakarzinoms (TNBC) in der adjuvanten oder neoadjuvanten Situation ist davon geprägt, dass eine Chemotherapie bei einem Teil der Patientinnen eine gute Wirksamkeit hat, was folgend zu erheblichen Verbesserung der Prognose führt. So konnte in neoadjuvanten Studien gezeigt werden, dass triple-negative Patientinnen, die eine PCR erreichen, ähnlich wie HER2-positive Patientinnen eine exzellente Prognose haben [59-66].

Im Falle einer fehlenden pCR nach neoadjuvanter Chemotherapie hatte die CREATE-X-Studie bei HER2-negativen Patientinnen eine adjuvante Therapie mit Capecitabin geprüft [67]. Insbesondere bei den triple-negativen Patientinnen hatte diese in Asien durchgeführte Studie einen Vorteil für das rückfallfreie Überleben (DFS) mit einer Hazard Ratio von 0,59 (95\%-KI: 0,39-0,87) gezeigt [68].

In einem anderen Studiensetting, aber mit derselben Fragestellung wurde die CIBOMA/2004-01_GEICAM/2003-11-Studie durchgeführt [69]. Zugelassen waren in dieser in Spanien und Lateinamerika durchgeführten Studie triple-negative Patientinnen nach einer durchgeführten adjuvanten oder neoadjuvanten Chemotherapie, die nach Abschluss der Therapie mit Capecitabin weiterbehandelt wurden oder keine weitere Therapie erhielten. Erwartungsgemäß war die Toxizität im experimentellen Arm höher. Zusätzlich konnte kein verbessertes rezidivfreies Überleben beobachtet werden (HR: 0,82 [95\%-KI: 0,63, 1,06], p=0,136). Lediglich in einer Subgruppe mit Non-basal TNBC-Karzinomen (EGFR und CK5/6 negativ) konnte ein Unterschied detektiert werden ( $p=0,020$, HR: 0,53 [95\%-KI: 0,31, 0,91]). Da die Studie aber insgesamt negativ war, wurde auch in der anschließenden Diskussion gefolgert, dass außerhalb der Bedingungen in der Create-X-Studie der Einsatz von Capecitabin bei Patientinnen mit TNBC nicht indiziert ist [69].

In einigen Studien ist die Wirksamkeit von Gemcitabin, nabPaclitaxel und Carboplatin beim frühen Mammakarzinom bereits untersucht worden [70-81]. Zusammengefasst zeigten diese Studien, dass eine Hinzunahme von Gemcitabin zu einer Standardtherapie zu keiner Verbesserung führte und in einem Vergleich zwischen einer Standardtherapie und einer platinhaltigen Therapie Letztere einen Vorteil erbrachte. In der ADAPT-Studie konnte bei triple-negativen Patientinnen nach einer neoadjuvanten Chemotherapie in einem Vergleich zwischen einer Behandlung mit nab-Paclitaxel und Gemcitabin vs. nab-Paclitaxel und Carboplatin eine höhere pCR-Rate (26 vs. $45 \%$ ) bei Patientinnen mit einer platinhaltigen Therapie gefunden werden [82]. In Bezug auf das rückfallfreie Überleben (DFS) fand die Studie keinen Unterschied in den beiden Behandlungsarmen [83]. Nun wurde in einer kürzlich vorgestellten Analyse die Frage nach möglichen prädiktiven Markern gestellt [84]. Während Patientinnen mit einer pCR und hoher PD1-Expression die beste Prognose hatten, konnten keine prädiktiven Marker für die Überlegenheit von Carboplatin bei TNBC in der neoadjuvanten Chemotherapie identifiziert werden. Bei Patientinnen mit pCR nach 12 Wochen und hohem Baseline PD1 (mRNA) führte die postoperative Fortsetzung der Chemotherapie mit 4 Zyklen Epirubicin und Cyclophosphamid nicht zu einer besseren Prognose. Die Entscheidung über eine Fortführung nach der neoadjuvanten Therapie war aber nicht randomisiert. Dies werteten die Autoren als Hinweis für eine mögliche zukünftige Deeskalationsgrundlage, auch wenn die Ergebnisse derzeit nur hypothesengenerierend und nicht als aktuelle Entscheidungsgrundlage zu werten sind [84].

\section{Adjuvante Therapie des primären hormonrezeptorpositiven HER2-negativen Mammakarzinoms}

Mit der Therapie der hormonrezeptorpositiven, HER2-negativen Mammakarzinompatientin in der adjuvanten Situation sind bislang hauptsächlich 3 Fragen verbunden: Bei welcher Risikokonstellation muss eine Chemotherapie durchgeführt werden? Was ist die optimale antiendokrine Therapie? Und wie lange sollte diese gegeben werden?

In Bezug auf die Frage nach der Chemotherapie ist bekannt, dass Patientinnen mit einem positiven Hormonrezeptorstatus, insbesondere mit einer niedrigen Proliferation, auf eine Chemotherapie nicht gut ansprechen $[60,62,85]$. Deswegen stellt sich die Frage, ob eine Chemotherapie in so einer Patientenpopulation überhaupt Sinn macht. Kürzlich zeigte die TAILOR-X-Studie, dass Patientinnen, die in einem Multi-Gen-Assay einen intermediären Score hinsichtlich des Rückfallrisikos erreicht hatten, von einer adjuvanten Chemotherapie gefolgt von einer Antihormontherapie im Vergleich zur alleinigen Antihormontherapie nicht profitieren 
- Tab. 2 Risikoreduktionen einer erweiterten antihormonellen Therapie mit Aromatasehemmern (AI) nach Tamoxifen (TAM), Al oder TAM, gefolgt von $\mathrm{Al}$ (nach [89]).

\begin{tabular}{|c|c|c|c|c|c|c|c|}
\hline \multirow[t]{2}{*}{ Vortherapie } & \multirow[t]{2}{*}{$\mathbf{n}$} & \multicolumn{2}{|l|}{ jedwedes Rezidiv } & \multicolumn{2}{|l|}{ Fernmetastasen } & \multicolumn{2}{|c|}{ Brustkrebs-Mortalität } \\
\hline & & RR (95\%-KI) & p-Wert & RR (95\%-KI) & p-Wert & RR (95\%-KI) & p-Wert \\
\hline 5 Jahre TAM & 7483 & $0,67(0,57-0,79)$ & $<0,00001$ & $0,77(0,63-0,93)$ & 0,008 & $0,77(0,59-1,00)$ & 0,05 \\
\hline 5 Jahre Al & 3322 & $0,76(0,61-0,95)$ & 0,2 & $0,78(0,59-1,04)$ & 0,09 & $0,99(0,68-1,44)$ & 0,97 \\
\hline 5-10 Jahre Tam, dann Al & 11387 & $0,82(0,73-0,93)$ & 0,002 & $0,92(0,80-1,07)$ & 0,29 & $0,93(0,77-1,12)$ & 0,45 \\
\hline alle Patientinnen & 22192 & $0,76(0,70-0,83)$ & $<0,00001$ & $0,85(0,77-0,95)$ & 0,004 & $0,89(0,77-1,02)$ & 0,09 \\
\hline Pat. mit N0 & 10620 & $0,82(0,71-0,95)$ & 0,009 & -1 & & -1 & \\
\hline Pat. mit 1-3 LK & 6919 & $0,74(0,64-0,85)$ & 0,00003 & -1 & & -1 & \\
\hline Pat. mit > $3 \mathrm{LK}$ & 1621 & $0,71(0,56-0,89)$ & 0,003 & -1 & & -1 & \\
\hline
\end{tabular}

[86]. In dieser Patientinnenpopulation könnte auf eine Chemotherapie somit verzichtet werden. Neulich präsentierte Lebensqualitätsdaten aus der TAILOR-X-Studie unterstreichen diesen Therapie-Entscheidungsansatz [87] (weitere Diskussion in [88]).

Bei der Frage nach der Länge der adjuvanten, antihormonellen Therapie mit Aromatasehemmern wurde bislang in den Leitlinien und Therapieempfehlungen eher für Patientinnen mit einem erhöhten Rückfallrisiko eine Therapie bis zum 10. Jahr nach Diagnose empfohlen als für Patientinnen mit einem niedrigeren Rückfallrisiko. Die Fallzahlen für solche Analysen waren in den jeweiligen Studien jedoch relativ klein. Ebenfalls stellt sich die Frage, ob eine erweiterte adjuvante Therapie mit einem Aromatasehemmer nach Tamoxifen genauso viel Benefit mit sich bringt wie nach einem Aromatasehemmer. Diese Fragen wurden nun von einer Metaanalyse der Early Breast Cancer Trialists Collaborative Group mit mehr als 22000 Patientinnen aus 11 Studien adressiert [89].

Die sehr umfangreichen Analysen untersuchten zum einen den Effekt von Aromatasehemmern nach 5 Jahren Tamoxifen, nach 5 Jahren Aromatasehemmer oder nach 5-10 Jahren einer Sequenz von Tamoxifen und Aromatasehemmern. Des Weiteren wurden Subgruppenanalysen in der Gesamtpopulation für Patientinnen mit 0, 1-3 und mehr als 3 befallenen Lymphknoten durchgeführt. Der Therapieeffekt war am größten in der Gruppe der Patientinnen, die nur mit Tamoxifen vorbehandelt waren, und nur marginal für Patientinnen, die eine 5-jährige Vortherapie mit Aromatasehemmern hatten. Die relativen Risiken für alle Analysen sind in - Tab. 2 dargestellt.

Bei der Analyse der relativen Risiken für ein Rezidiv in Abhängigkeit vom Nodalstatus zeigte sich, dass der größte Effekt in der Population der Patientinnen gesehen werden konnte, die mehr befallene Lymphknoten bei der Primärdiagnose hatten ( $\bullet$ Tab. 2) [89]. Wichtig ist auch zu beachten, dass das Risiko für Knochenbrüche durch die erweiterte Al-Therapie um 24\% erhöht wurde [89].

In einem ähnlichen Kontext ist die kürzlich von Ohtani et al. präsentierte AERAS-Studie beachtenswert: Die erweiterte Therapie mit Anastrozol für insgesamt 10 Jahre führte bei 840 Patientinnen zu einer Halbierung der DFS-Events im Vergleich zu 843 Patientinnen, deren endokrine Therapie nach 5 Jahren beendet wurde (HR 0,548, $p=0,0004)$. Ein Einfluss auf das Gesamtüberleben konnte nicht gezeigt werden. Gleichzeitig war die Frakturrate mit
2,8\% im erweiterten Therapiearm mehr als doppelt so hoch wie im Kontrollarm (1,1\%) [90].

Eine weitere Möglichkeit der Intensivierung der adjuvanten endokrinen Therapie besteht in der Kombination der endokrinen Therapie mit Substanzen, die in der metastasierten Situation bereits gezeigt haben, dass sie zumindest für einen Teil der Patientinnen eine endokrine Resistenz überwinden können. Nach der Einführung von Everolimus in die Behandlung von Patientinnen mit metastasiertem Mammakarzinom [91,92] wurden folgend auch adjuvante Studien begonnen (z.B. NCT01674140, NCT01805271), deren Veröffentlichung noch aussteht. Eine weitere Möglichkeit ist die Kombination mit CDK4/6-Inhibitoren, welche ein günstigeres Nebenwirkungsprofil haben. Diesbezüglich gab es kürzlich profunde Ergebnisse aus der neoadjuvanten Therapiesituation. Dowsett et al. präsentierten die Ergebnisse der Pallet-Studie: Hier wurde Palbociclib zusätzlich zu einer 3-monatigen neoadjuvanten endokrinen Therapie mit Letrozol gegeben. Es zeigte sich, dass durch Palbociclib die antiproliferative Wirkung des Aromatasehemmers substanziell verstärkt wird: Der Anteil der Tumoren, die während der neoadjuvanten Therapie einen kompletten Zellzyklus-Arrest in Form eines Ki-67-Wertes < 2,7\% erfuhren, konnte durch Hinzunahme von Palbociclib von 58,5 auf 90,4\% erhöht werden [93].

Mit neuen, wirksamen Kombinationstherapien stehen weitere Möglichkeiten zur Verfügung die adjuvante Therapie der hormonrezeptorpositiven, HER2-negativen Patientin zunehmend zu verbessern. So werden zurzeit für alle CDK4/6-Inhibitoren adjuvante Therapiestudien durchgeführt (Penelope, PALLAS, MonarchE und NataLEE).

Mit der Weiterentwicklung der adjuvanten antihormonellen Therapie stellt sich insbesondere bei einem bekannt ungünstigeren Nebenwirkungsprofil die Frage nach der Compliance, die schon bei den adjuvanten Studien mit einer antiendokrinen Monotherapie diskutiert wurde. Einige Studien haben über die Adhärenz berichtet [94-98], welche zwischen 60 und 90\% lag. Es wird interessant sein, wie diese von einer Kombination mit einem CDK4/6-Inhibitor beeinflusst wird, zumal bekannt ist, dass Nebenwirkungen einer der Hauptprädiktoren für eine Nichtadhärenz sind. 


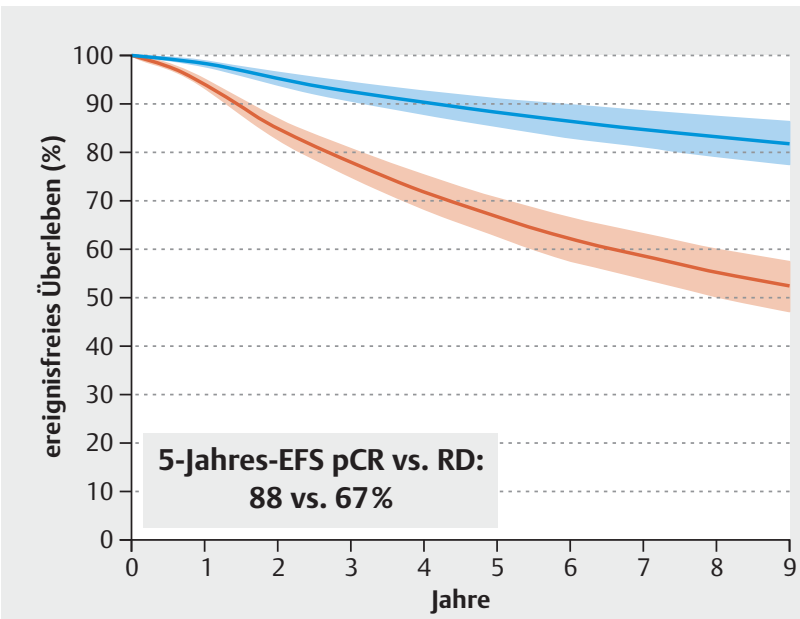

- Abb. 2 Ereignisfreie 5-Jahres-Überlebenswahrscheinlichkeit nach neoadjuvanter Chemotherapie und mit pathologischer Komplettremission (blau) oder ohne pCR (rot).

\section{Therapie des primären HER2-positiven Mammakarzinoms}

\section{Vorteile der neoadjuvanten Therapie}

Die neoadjuvante Systemtherapie erlaubt neben einer Senkung der operativen Morbidität (mehr Brusterhaltung, weniger axilläre Lymphonodektomien) die In-vivo-Sensitivitätstestung $[99,100]$. Anhand der Wirkung der neoadjuvanten Systemtherapie auf den Primärtumor kann deren Effekt auf die Langzeitprognose, möglicherweise durch die Zerstörung bzw. Kontrolle von Mikrometastasen, abgeschätzt werden $[62,101]$.

Eine kürzliche Metaanalyse unterlegte nochmals die prognostische Bedeutung des Erreichens einer pathologischen Komplettremission (pathological complete remission, pCR) nach neoadjuvanter Chemotherapie [102]. Nach Auswertung von 52 Studien (51,1\% randomisiert; 6,1\% einarmig; $42,8 \%$ retrospektiv) mit 27895 Patientinnen und einer medianen Nachbeobachtung von 4 Jahren wurde bestätigt, dass durch Erreichen einer PCR das Risiko für ein Brustkrebsereignis signifikant um 69\% (HR 0,31; 95\%-KI $0,24-0,39$ ) und das Risiko zu versterben um 78\% sinkt (HR 0,22; 95\%-KI 0,15-1,30). Der absolute Effekt nach 5 Jahren auf DFS und Overall Survival (OS) betrug 21 bzw. 19\% ( $\triangleright$ Abb. 2 und 3). Der absolute Effekt war mit kurzer Nachbeobachtungszeit am größten bei Patientinnen mit triple-negativem Mammakarzinom, gefolgt von Patientinnen mit HER2-positivem und hormonrezeptorpositivem, HER2-negativem Mammakarzinom ( $\Delta$ im 5-Jahre-EFS 33 vs. 23 vs. $9 \%$ ). Ein $\Delta$ in der pCR-Rate von $20 \%$ übertrug sich in den Studien statistisch gesehen in eine Senkung des Ereignisrisikos um ca. 20\% [102]. Eine zusätzliche postoperative Chemotherapie nach Erreichen einer PCR verbesserte die Prognose nicht.

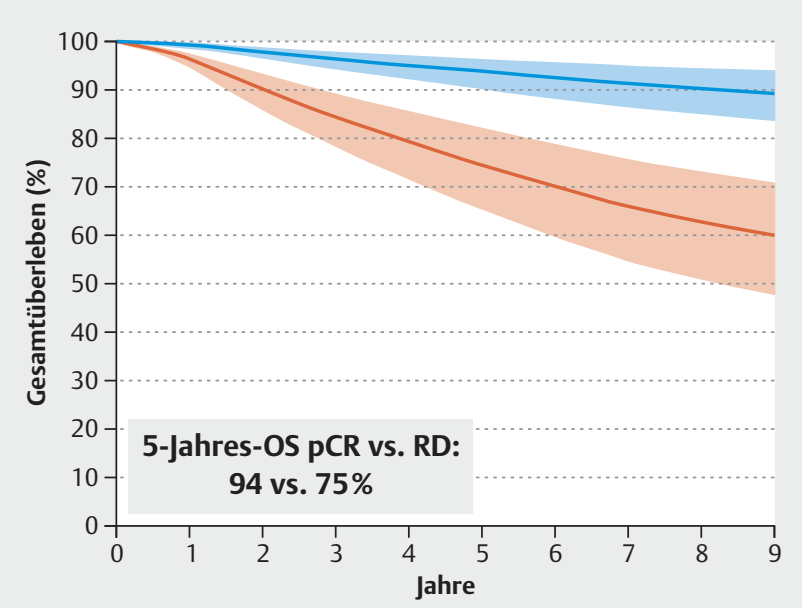

- Abb. 3 5-Jahres-Gesamt-Überlebenswahrscheinlichkeit nach neoadjuvanter Chemotherapie und mit pathologischer Komplettremission (blau) oder ohne pCR (rot).

\section{Verbesserung der Prognose durch Wechsel auf T-DM1 bei non-pCR}

Die Phase-III-CREATE X-Studie hat erstmals gezeigt, dass durch Anpassung der postoperativen Therapie an das pathologische Ansprechen auf die neoadjuvante Therapie das Rezidiv- und Sterblichkeitsrisikos signifikant gesenkt werden kann [67]. Während in der CREATE X-Studie nur Patientinnen mit einem HER2-negativen Mammakarzinom eingeschlossen wurden, die durch eine neoadjuvante Chemotherapie keine pCR erreichten, testete die KATHERINE-Studie den gleichen Ansatz bei Patientinnen mit einem HER2-positiven Mammakarzinom [103, 104]. In diese Studie wurden 1486 Patientinnen mit primärem HER2-positivem Mammakarzinom eingeschlossen, die nach einer neoadjuvanten Standardtherapie mit mindestens einem Taxan und Trastuzumab für mindestens 9 Wochen keine pCR erreicht hatten. Die neoadjuvante Therapie konnte Anthrazykline und eine duale Anti-HER2-Blockade beinhalten. Postoperativ wurden die Patientinnen randomisiert und erhielten parallel zur lokoregionären und bei Hormonrezeptorexpression endokrinen Standardtherapie entweder Trastuzumab Emtansin (T-DM1) 3,6 mg/kg oder Trastuzumab 6 mg/ $\mathrm{kg}$ alle 3 Wochen über 14 Zyklen. Prospektiv stratifiziert wurde nach Operabilität (primär operabel vs. inoperabel), Hormonrezeptorstatus (positiv vs. negativ), Art der neoadjuvanten AntiHER2-Therapie (Trastuzumab vs. duale Blockade mit Trastuzumab und Pertuzumab) und dem Nodalstatus nach abschließender Operation (ypN0 vs. ypN+). Mit einer medianen Nachbeobachtungszeit von 41 Monaten verbesserte der Wechsel auf T-DM1 den primären Endpunkt, das invasive krankheitsfreie Überleben nach 3 Jahren (invasive disease-free survival, IDFS), signifikant von 77,0 auf $88,3 \%(\Delta 11,3 \%$; HR 0,50 ; $95 \%-K I \quad 0,39-0,64$; $\mathrm{p}<0,0001)(\triangleright$ Abb. 4). Der relative Effekt war in allen stratifizierten Subgruppen gleich, insbesondere auch bei Patientinnen mit sehr kleinem Tumorrest ( $\leq$ ypT1b ypN0) und bei solchen, die neoadjuvant eine duale Anti-HER2-Blockade erhalten hatten. Dies 


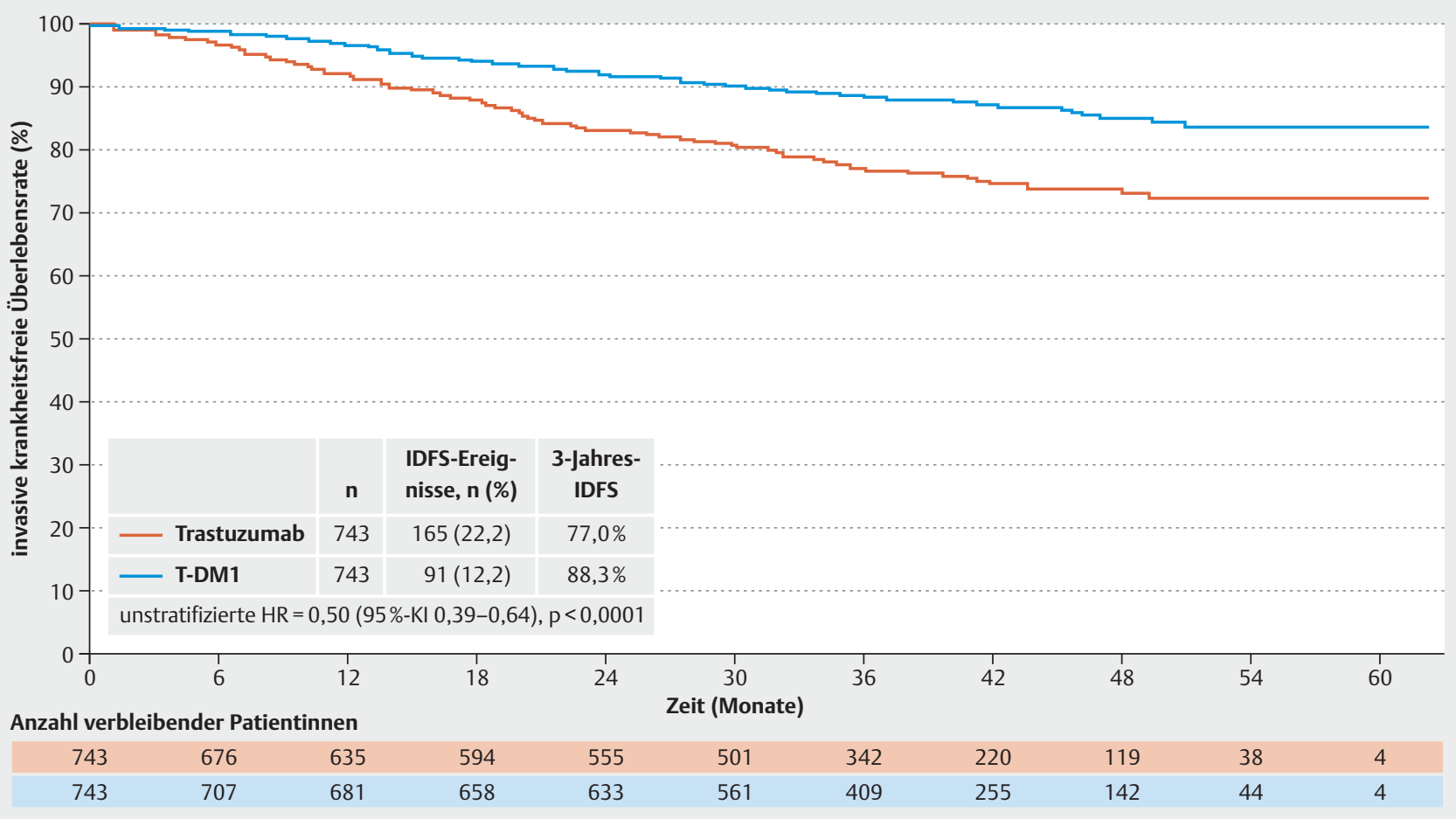

- Abb. 4 Invasives rückfallfreies Überleben beim Vergleich der beiden Randomisationsarme der Katherine-Studie (modifiziert nach [104]).

scheint auch deswegen wichtig zu erwähnen, weil die neoadjuvante Therapie mit Trastuzumab und Pertuzumab ähnlich wie in klinischen Studien auch in Real-World-Analysen eine höhere PCRRate gezeigt hatte [105]. Auch das metastasenfreie Überleben (distant disease-free survival, DDFS) nach 3 Jahren wurde signifikant von 83,0 auf $89,7 \%$ verbessert ( $\Delta 6,7 \%$; HR 0,60; 95\%-KI $0,45-0,79)$. Dieser Nutzen wurde erreicht auf Kosten einer klinisch gut beherrschbaren Zunahme von Thrombopenien (Grad $\geq 3 \Delta 5,7 \%$ ), erhöhter Leberwerte (Grad $\geq 3 \Delta$ ca. $1 \%$ ) und Polyneuropathien (Grad $\geq 3 \Delta 1,4 \%$ ) [103]. Damit stellt der Wechsel auf T-DM1 bei non-pCR nach einer adäquaten neoadjuvanten Systemtherapie beim HER2-positiven primären Mammakarzinom einen neuen Therapiestandard dar.

\section{Dauer der Trastuzumabbehandlung}

Bei Patientinnen mit HER2-positivem, primärem Mammakarzinom, welche die Indikation für eine Behandlung mit Trastuzumab haben, wird immer wieder die Frage gestellt, ob eine Therapiedauer von 1 Jahr zwingend erforderlich ist oder ob eventuell eine kürzere Therapie erwogen werden kann [106]. In diesem Zusammenhang wurden kürzlich die finalen Überlebensdaten der PhaseIII-PHARE-Studie vorgestellt [107]. In dieser Nichtunterlegenheitsstudie erhielten 3384 Patientinnen mit HER2-positivem, primärem Mammakarzinom (57,7\% hormonrezeptorpositiv; 44,6\% nodal-positiv; ca. 43\% Trastuzumabtherapie sequenziell), die nach 6 Monaten unter Trastuzumab noch ereignisfrei waren, randomisiert entweder weitere 6 Monate Trastuzumab oder keine weitere Anti-HER2-Therapie. Mit einer medianen Nachbeobachtungszeit von 7,5 Jahren waren sowohl das DFS als auch das DDFS und OS nach nur 6-monatiger Trastuzumabtherapie nicht eindeutig gleich gut wie nach 1 Jahr Trastuzumab. Die obere Grenze des 95\%-KI der HR lag über dem vordefinierten Maximalwert von 1,15. In der Subgruppe, bei der Trastuzumab schon während der Chemotherapie gestartet wurde, waren allerdings beide Therapiearme gleich effektiv. Dennoch konnte die Gleichwertigkeit von 6 vs. 12 Monaten Trastuzumabbehandlung insgesamt nicht mit der ausreichenden Sicherheit gezeigt werden, sodass eine Trastuzumabtherapie über 1 Jahr der Standard bleibt.

\section{Ausblick}

Mit der KATHERINE-Studie wurde eine große adjuvante Studie vorgestellt, die für die neoadjuvant behandelte HER2-positive Patientinnenpopulation eine bedeutende Verringerung des Rückfallrisikos demonstrieren kann. Dies ist nicht nur für diese Patientengruppe von Bedeutung, sondern auch für Patientinnen mit anderen Tumorbiologien. Patientinnen mit hormonrezeptorpositivem, HER2-negativen Mammakarzinom sind in einem ähnlichen, postneoadjuvanten Therapiekonzept mit Palbociclib behandelt worden. Erste Ergebnisse werden für Mitte 2019 erwartet. Die Olympia-Studie hat ebenfalls post-neoadjuvante Patientinnen mit einer BRCA-Mutation für eine Therapie mit Olaparib eingeschlossen.

Unabhängig von der post-neoadjuvanten Situation werden zurzeit 3 große adjuvante Studien mit CDK4/6-Inhibitoren durchgeführt, die ebenfalls ein Potenzial für eine bedeutsame TherapieEffektivität haben. 


\section{Danksagung}

Diese Arbeit entstand teilweise in Folge von Förderungen der Firma Riemser und des PRAEGNANT-Netzwerks, das von den Firmen Hexal, Pfizer, Celgene, Daiichi-Sankyo, Roche, Merrimack, Eisai, and Novartis unterstützt wird. Keine der Fimen hatte einen Anteil bei der Verfassung dieses Manuskriptes. Für den Inhalt des Manuskriptes sind alleine die Autoren verantwortlich.

Interessenkonflikt

A.D.H. hat Sprecher- und Beraterhonorare von AstraZeneca, Genomic Health, Roche, Novartis, Celgene, Lilly, MSD, Eisai, Teva, Tesaro, DaiichiSankyo, Hexal und Pfizer erhalten. N. N. hat Beraterhonorare von Janssen-Cilag und Novartis bezogen. F. O. hat Sprecher- und Beraterhonorare von Amgen, AstraZeneca, Bayer, BMS, Boehringer-Ingelheim, Chugai, Celgene, Cellex, Eisai, Gilead, Hexal, Ipsen, Janssen-Cilag, Merck, MSD, Novartis, Riemser, Roche, Tesaro und Teva erhalten. F.-A.T. hat Honorare von AstraZeneca, Genomic Health und Novartis erhalten. H.-C. K. hat Honorare von Carl Zeiss meditec, Teva, Theraclion, Novartis, Amgen, AstraZeneca, Pfizer, Janssen-Cilag, GSK, LIV Pharma, Roche und Genomic Health bezogen. P. A. F. hat Honorare von Novartis, Pfizer, Roche, Amgen, Celgene, Daiichi-Sankyo, AstraZeneca, Merck-Sharp \& Dohme, Eisai, Puma und Teva erhalten. An seiner Einrichtung werden Forschungsarbeiten mit finanzieller Unterstützung von Novartis und Biontech durchgeführt. H.T. hat Honorare von Novartis, Roche, Celgene, Teva, Pfizer sowie Reisekostenzuschüsse von Roche, Celgene und Pfizer erhalten. J. E. hat Honorare von Astra Zeneca, Roche, Celgene, Novartis, Lilly, Pfizer, Pierre Fabre, Teva sowie Reisekostenzuschüsse von Celgene, Pfizer, Teva und Pierre Fabre erhalten. M. P. L. war Mitglied von Beratungsgremien für AstraZeneca, MSD, Novartis, Pfizer, Eisai, Genomic Health und Roche und hat Vortragshonorare von MSD, Lilly, Roche, Novartis, Pfizer, Genomic Health, AstraZeneca, medac und Eisai bezogen. V. M. hat Sprecherhonorare von Amgen, AstraZeneca, Celgene, Daiichi-Sankyo, Eisai, Pfizer, Novartis, Roche, Teva, Janssen-Cilag sowie Beraterhonorare von Genomic Health, Hexal, Roche, Pierre Fabre, Amgen, Novartis, MSD, Daiichi-Sankyo und Eisai, Lilly, Tesaro und Nektar erhalten. E. B. hat Honorare von Novartis, Celgene, Riemser, Pfizer, Hexal, Amgen und onkowissen.de für Beratung sowie Tätigkeiten in den Bereichen Management von klinischer Forschung und medizinische Fortbildung erhalten. A.S. hat Honorare von Roche, Celgene, AstraZeneca, Novartis, Pfizer, Zuckschwerdt Verlag GmbH, Georg Thieme Verlag, Aurikamed $\mathrm{GmbH}, \mathrm{MCl}$ Deutschland $\mathrm{GmbH}$, bsh medical communications $\mathrm{GmbH}$ und promedicis $\mathrm{GmbH}$ bezogen. W. J. hat Honorare und Forschungsmittel von Novartis, Roche, Pfizer, Lilly, AstraZeneca, Chugai, Sanofi, Daichi, Tesaro erhalten. F. S. war Mitglied von Beratungsgremien für Novartis, Lilly, Amgen und Roche und hat Vortragshonorare von Roche, AstraZeneca, MSD, Novartis und Pfizer erhalten. A.W. war Mitglied von Beratungsgremien für Novartis, Lilly, Amgen, Pfizer, Roche, Tesaro, Eisai und hat Vortragshonorare von Novartis, Pfizer, Aurikamed, Roche und Celgene erhalten. D. L. hat Honorare von Amgen, AstraZeneca, Celgene, Lilly, Loreal, MSD, Novartis, Pfizer, Tesaro und Teva erhalten. T.N. F. war Mitglied von Beratungsgremien für Amgen, Daichi Sankyo, Novartis, Pfizer und Roche und hat Vortragshonorare von Amgen, Celgene, Daichi Sankyo, Roche, Novartis und Pfizer bezogen.

\section{Literatur}

[1] Brennan M, Gass P, Haberle L et al. The effect of participation in neoadjuvant clinical trials on outcomes in patients with early breast cancer. Breast Cancer Res Treat 2018. doi:10.1007/s10549-018-4829-4

[2] Hennigs A, Riedel F, Marme F et al. Changes in chemotherapy usage and outcome of early breast cancer patients in the last decade. Breast Cancer Res Treat 2016; 160: 491-499
[3] Kreienberg R, Wockel A, Wischnewsky M. Highly significant improvement in guideline adherence, relapse-free and overall survival in breast cancer patients when treated at certified breast cancer centres: An evaluation of 8323 patients. Breast 2018; 40: 54-59

[4] Beckmann MW, Brucker C, Hanf V et al. Quality assured health care in certified breast centers and improvement of the prognosis of breast cancer patients. Onkologie 2011; 34: 362-367

[5] Early Breast Cancer Trialists' Collaborative Group. Adjuvant bisphosphonate treatment in early breast cancer: meta-analyses of individual patient data from randomised trials. Lancet 2015; 386: 1353-1361

[6] Early Breast Cancer Trialists' Collaborative Group. Aromatase inhibitors versus tamoxifen in early breast cancer: patient-level meta-analysis of the randomised trials. Lancet 2015; 386: 1341-1352

[7] Early Breast Cancer Trialists' Collaborative Group (EBCTCG). Comparisons between different polychemotherapy regimens for early breast cancer: meta-analyses of long-term outcome among 100,000 women in 123 randomised trials. Lancet 2012; 379: 432-444

[8] Wunderle M, Olmes G, Nabieva N et al. Risk, Prediction and Prevention of Hereditary Breast Cancer - Large-Scale Genomic Studies in Times of Big and Smart Data. Geburtsh Frauenheilk 2018; 78: 481-492

[9] Fasching PA, Brucker SY, Fehm TN et al. Biomarkers in Patients with Metastatic Breast Cancer and the PRAEGNANT Study Network. Geburtsh Frauenheilk 2015; 75: 41-50

[10] Fasching PA, Ekici AB, Adamietz BR et al. Breast Cancer Risk - Genes, Environment and Clinics. Geburtsh Frauenheilk 2011; 71: 1056-1066

[11] Shimelis H, LaDuca H, Hu C et al. Triple-Negative Breast Cancer Risk Genes Identified by Multigene Hereditary Cancer Panel Testing. J Natl Cancer Inst 2018. doi:10.1093/jnci/djy106

[12] Couch FJ, Shimelis H, Hu C et al. Associations Between Cancer Predisposition Testing Panel Genes and Breast Cancer. JAMA Oncol 2017; 3 : 1190-1196

[13] Kraus C, Hoyer J, Vasileiou G et al. Gene panel sequencing in familial breast/ovarian cancer patients identifies multiple novel mutations also in genes others than BRCA1/2. Int J Cancer 2017; 140: 95-102

[14] Hauke J, Horvath J, Gross E et al. Gene panel testing of 5589 BRCA1/2negative index patients with breast cancer in a routine diagnostic setting: results of the German Consortium for Hereditary Breast and Ovarian Cancer. Cancer Med 2018; 7: 1349-1358

[15] Couch F], Hart SN, Sharma P et al. Inherited mutations in 17 breast cancer susceptibility genes among a large triple-negative breast cancer cohort unselected for family history of breast cancer. J Clin Oncol 2015; 33 : 304-311

[16] Fasching PA, Hu C, Hart SN et al. Cancer predisposition genes in metastatic breast cancer - Association with metastatic pattern, prognosis, patient and tumor characteristics [abstract]. In: Proceedings of the 2017 San Antonio Breast Cancer Symposium; 2017 Dec 5-9; San Antonio, TX Philadelphia (PA): AACR. Cancer Res 2018; 78: Abstr. PD1-02

[17] Hoyer J, Vasileiou G, Uebe $S$ et al. Addition of triple negativity of breast cancer as an indicator for germline mutations in predisposing genes increases sensitivity of clinical selection criteria. BMC Cancer 2018; 18: 926

[18] Antoniou AC, Casadei S, Heikkinen T et al. Breast-cancer risk in families with mutations in PALB2. N Engl J Med 2014; 371: 497-506

[19] Couch F], Hu C, Hart SN et al. Age-related breast cancer risk estimates for the general population based on sequencing of cancer predisposition genes in 19,228 breast cancer patients and 20,211 matched unaffected controls from US based cohorts in the CARRIERS study. San Antonio Breast Cancer Symposium 2018; Abstr. GS2-01

[20] Fasching PA, Schneeweiss A, Kolberg HC et al. Translational highlights in breast cancer research and treatment: recent developments with clinical impact. Curr Opin Obstet Gynecol 2019; 31: 67-75

[21] Ghoussaini M, Fletcher O, Michailidou K et al. Genome-wide association analysis identifies three new breast cancer susceptibility loci. Nat Genet 2012; 44: 312-318 
[22] Garcia-Closas M, Couch F], Lindstrom S et al. Genome-wide association studies identify four ER negative-specific breast cancer risk loci. Nat Genet 2013; 45: 392-398, 398e1-398e2

[23] French JD, Ghoussaini M, Edwards SL et al. Functional variants at the $11 q 13$ risk locus for breast cancer regulate cyclin D1 expression through long-range enhancers. Am J Hum Genet 2013; 92: 489-503

[24] Bojesen SE, Pooley KA, Johnatty SE et al. Multiple independent variants at the TERT locus are associated with telomere length and risks of breast and ovarian cancer. Nat Genet 2013; 45: 371-384, 384e1-384e2

[25] Michailidou K, Beesley J, Lindstrom S et al. Genome-wide association analysis of more than 120,000 individuals identifies 15 new susceptibility loci for breast cancer. Nat Genet 2015; 47: 373-380

[26] Michailidou K, Hall P, Gonzalez-Neira A et al. Large-scale genotyping identifies 41 new loci associated with breast cancer risk. Nat Genet 2013; 45: 353-361, 361e1-361e2

[27] Michailidou K, Lindstrom S, Dennis J et al. Association analysis identifies 65 new breast cancer risk loci. Nature 2017; 551: 92-94

[28] Mavaddat N, Pharoah PD, Michailidou K et al. Prediction of breast cancer risk based on profiling with common genetic variants. J Natl Cancer Inst 2015; 107: pii: djv036

[29] Mavaddat N, Michailidou K, Dennis J et al. Polygenic Risk Scores for Prediction of Breast Cancer and Breast Cancer Subtypes. Am J Hum Genet 2018. doi:10.1016/j.ajhg.2018.11.002

[30] Antoniou AC, Wang X, Fredericksen ZS et al. A locus on 19p13 modifies risk of breast cancer in BRCA1 mutation carriers and is associated with hormone receptor-negative breast cancer in the general population. Nat Genet 2010; 42: 885-892

[31] Haberle L, Hein A, Rubner M et al. Predicting Triple-Negative Breast Cancer Subtype Using Multiple Single Nucleotide Polymorphisms for Breast Cancer Risk and Several Variable Selection Methods. Geburtsh Frauenheilk 2017; 77: 667-678

[32] Haiman CA, Chen GK, Vachon CM et al. A common variant at the TERTCLPTM1 L locus is associated with estrogen receptor-negative breast cancer. Nat Genet 2011; 43: 1210-1214

[33] Milne RL, Benitez J, Nevanlinna $\mathrm{H}$ et al. Risk of estrogen receptor-positive and -negative breast cancer and single-nucleotide polymorphism 2q35rs13387042. J Natl Cancer Inst 2009; 101: 1012-1018

[34] Milne RL, Kuchenbaecker KB, Michailidou K et al. Identification of ten variants associated with risk of estrogen-receptor-negative breast cancer. Nat Genet 2017; 49: 1767-1778

[35] Purrington KS, Slager S, Eccles D et al. Genome-wide association study identifies 25 known breast cancer susceptibility loci as risk factors for triple-negative breast cancer. Carcinogenesis 2014; 35: 1012-1019

[36] Stevens KN, Fredericksen Z, Vachon CM et al. 19p13.1 is a triple-negative-specific breast cancer susceptibility locus. Cancer Res 2012; 72: 1795-1803

[37] Stevens KN, Vachon CM, Lee AM et al. Common breast cancer susceptibility loci are associated with triple-negative breast cancer. Cancer Res 2011; 71: 6240-6249

[38] Broeks A, Schmidt MK, Sherman ME et al. Low penetrance breast cance susceptibility loci are associated with specific breast tumor subtypes: findings from the Breast Cancer Association Consortium. Hum Mol Genet $2011 ; 20: 3289-3303$

[39] Figueroa JD, Garcia-Closas M, Humphreys M et al. Associations of common variants at 1p11.2 and 14q24.1 (RAD51L1) with breast cancer risk and heterogeneity by tumor subtype: findings from the Breast Cancer Association Consortium. Hum Mol Genet 2011; 20: 4693-4706

[40] Yang XR, Chang-Claude J, Goode EL et al. Associations of breast cancer risk factors with tumor subtypes: a pooled analysis from the Breast Cancer Association Consortium studies. I Natl Cancer Inst 2011; 103: 250 263
[41] Rudolph A, Song M, Brook MN et al. Joint associations of a polygenic risk score and environmental risk factors for breast cancer in the Breast Cancer Association Consortium. Int J Epidemiol 2018. doi:10.1093/ije/ dy 242

[42] Vachon CM, Pankratz VS, Scott CG et al. The contributions of breast density and common genetic variation to breast cancer risk. J Natl Cancer Inst 2015; 107: pii: dju397

[43] Vachon CM, Scott CG, Fasching PA et al. Common breast cancer susceptibility variants in LSP1 and RAD51L1 are associated with mammographic density measures that predict breast cancer risk. Cancer Epidemiol Biomarkers Prev 2012; 21: 1156-1166

[44] Cutress RI, McIntosh SA, Potter S et al. Opportunities and priorities for breast surgical research. Lancet Oncol 2018; 19: e521-e533

[45] Kim HJ, Dominici L, Rosenberg S et al. Surgical treatment after neoadjuvant systemic therapy in young women with breast cancer: Results from a prospective cohort study. San Antonio Breast Cancer Symposium 2018; Abstr. GS6-01

[46] Rosenberg SM, O'Neill A, Sepucha K et al. The impact of breast cancer surgery on quality of life: Long term results from E5103. San Antonio Breast Cancer Symposium 2018; Abstr. GS6-05

[47] Dominici LS, Hu J, King TA et al. Local therapy and quality of life outcomes in young women with breast cancer. San Antonio Breast Cancer Symposium 2018; Abstr. GS6-06

[48] Bani MR, Beckmann K, Engel J et al. Correlates of the desire for improved cosmetic results after breast-conserving therapy and mastectomy in breast cancer patients. Breast 2008; 17: 640-645

[49] Kuehn T, Bauerfeind I, Fehm T et al. Sentinel-lymph-node biopsy in patients with breast cancer before and after neoadjuvant chemotherapy (SENTINA): a prospective, multicentre cohort study. Lancet Oncol 2013; 14: 609-618

[50] Kolberg HC, Liedtke C, Bauerfeind I et al. Residual axillary involvement in early breast cancer in patients with positive sentinel nodes after neoadjuvant chemotherapy (NACT). San Antonio Breast Cancer Symposium 2018; Abstr. PD8-02

[51] Liedtke C, Kolberg HC, Kerschke L et al. Systematic analysis of parameters predicting pathological axillary status (ypN0 vs. ypN+) in patients with breast cancer converting from $\mathrm{cN}+$ to ycN0 through primary systemic therapy (PST). Clin Exp Metastasis 2018; 35: 777-783

[52] Giuliano AE, Hunt KK, Ballman KV et al. Axillary dissection vs. no axillary dissection in women with invasive breast cancer and sentinel node metastasis: a randomized clinical trial. JAMA 2011; 305: 569-575

[53] Rutgers E], Donker M, Poncet C et al. Radiotherapy or surgery of the axilla after a positive sentinel node in breast cancer patients: 10 year follow up results of the EORTC AMAROS trial (EORTC10981/22023). San Antonio Breast Cancer Symposium 2018; Abstr. GS4-01

[54] Vicini FA, Cecchini RS, White JR et al. Primary results of NSABP B-39/ RTOG 0413 (NRG Oncology): A randomized phase III study of conventional whole breast irradiation (WBI) versus partial breast irradiation (PBI) for women with stage 0 , I, or II breast cancer. San Antonio Breast Cancer Symposium 2018; Abstr. GS4-02

[55] Kommission Mamma der Arbeitsgemeinschaft Gynäkologische Onkologie e.V. in der Deutschen Gesellschaft für Gynäkologie und Geburtshilfe e.V. sowie in der Deutschen Krebsgesellschaft e.V. Diagnostik und Therapie von Patientinnen mit primärem und metastasiertem Brustkrebs. Online: https://wwwago-onlinede/fileadmin/downloads/leitlinien/ mamma/2017-03/AGO_deutsch/PDF_Gesamtdatei_deutsch/Alle_ aktuellen_Empfehlungen_2018pdf 2018; Stand: 07.07.2018

[56] Wockel A, Festl ], Stuber T et al. Interdisciplinary Screening, Diagnosis, Therapy and Follow-up of Breast Cancer. Guideline of the DGGG and the DKG (S3-Level, AWMF Registry Number 032/045OL, December 2017) - Part 2 with Recommendations for the Therapy of Primary, Recurrent and Advanced Breast Cancer. Geburtsh Frauenheilk 2018; 78 . 1056-1088 
[57] Wockel A, Festl ], Stuber T et al. Interdisciplinary Screening, Diagnosis, Therapy and Follow-up of Breast Cancer. Guideline of the DGGG and the DKG (S3-Level, AWMF Registry Number 032/045OL, December 2017) - Part 1 with Recommendations for the Screening, Diagnosis and Therapy of Breast Cancer. Geburtsh Frauenheilk 2018; 78: 927-948

[58] Dodwell D, Taylor C, McGale P et al. Regional lymph node irradiation in early stage breast cancer: An EBCTCG meta-analysis of 13,000 women in 14 trials. San Antonio Breast Cancer Symposium 2018; Abstr. GS4-02

[59] Cortazar P, Geyer CE jr. Pathological complete response in neoadjuvant treatment of breast cancer. Ann Surg Oncol 2015; 22: 1441-1446

[60] Fasching PA, Heusinger K, Haeberle L et al. Ki67, chemotherapy response, and prognosis in breast cancer patients receiving neoadjuvant treatment. BMC Cancer 2011; 11: 486

[61] Fasching PA, Loibl S, Hu C et al. BRCA1/2 Mutations and Bevacizumab in the Neoadjuvant Treatment of Breast Cancer: Response and Prognosis Results in Patients With Triple-Negative Breast Cancer From the GeparQuinto Study. J Clin Oncol 2018. doi:10.1200/JCO.2017.77.2285

[62] von Minckwitz G, Untch M, Blohmer JU et al. Definition and impact of pathologic complete response on prognosis after neoadjuvant chemotherapy in various intrinsic breast cancer subtypes. J Clin Oncol 2012; 30: 1796-1804

[63] Wunderle M, Gass P, Haberle L et al. BRCA mutations and their influence on pathological complete response and prognosis in a clinical cohort of neoadjuvantly treated breast cancer patients. Breast Cancer Res Treat 2018; 171: 85-94

[64] Untch M, Fasching PA, Konecny GE et al. Pathologic complete response after neoadjuvant chemotherapy plus trastuzumab predicts favorable survival in human epidermal growth factor receptor 2-overexpressing breast cancer: results from the TECHNO trial of the AGO and GBG study groups. J Clin Oncol 2011; 29: 3351-3357

[65] Untch M, von Minckwitz G, Konecny GE et al. PREPARE trial: a randomized phase III trial comparing preoperative, dose-dense, dose-intensified chemotherapy with epirubicin, paclitaxel, and CMF versus a standarddosed epirubicin-cyclophosphamide followed by paclitaxel with or without darbepoetin alfa in primary breast cancer-outcome on prognosis. Ann Oncol 2011; 22: 1999-2006

[66] Untch M, Fasching PA, Konecny GE et al. PREPARE trial: a randomized phase III trial comparing preoperative, dose-dense, dose-intensified chemotherapy with epirubicin, paclitaxel and CMF versus a standard-dosed epirubicin/cyclophosphamide followed by paclitaxel \pm darbepoetin alfa in primary breast cancer-results at the time of surgery. Ann Oncol 2011; 22: 1988-1998

[67] Masuda N, Lee SJ, Ohtani S et al. Adjuvant Capecitabine for Breast Cancer after Preoperative Chemotherapy. N Engl J Med 2017; 376: 2147-2159

[68] Adams S, Loi S, Toppmeyer DL et al. KEYNOTE-086 cohort B: Pembrolizumab monotherapy for PD-L1-positive, previously untreated, metastatic triple-negative breast cancer (mTNBC) [abstract]. In: Proceedings of the 2017 San Antonio Breast Cancer Symposium; 2017 Dec 5-9; San Antonio, TX Philadelphia (PA): AACR. Cancer Res 2018; 78: Abstr. PF6-10

[69] Martín M, Barrios CH, Torrecillas L et al. Efficacy results from CIBOMA/ 2004-01_GEICAM/2003-11 study: A randomized phase III trial assessing adjuvant capecitabine after standard chemotherapy for patients with early triple negative breast cancer. San Antonio Breast Cancer Symposium 2018; Abstr. GS2-04

[70] Gass P, Lux MP, Rauh C et al. Prediction of pathological complete response and prognosis in patients with neoadjuvant treatment for triplenegative breast cancer. BMC Cancer 2018; 18: 1051

[71] von Minckwitz G, Schneeweiss A, Loibl S et al. Neoadjuvant carboplatin in patients with triple-negative and HER2-positive early breast cancer (GeparSixto; GBG 66): a randomised phase 2 trial. Lancet Oncol 2014; 15: $747-756$
[72] Loibl S, Weber KE, Timms KM et al. Survival analysis of carboplatin added to an anthracycline/taxane-based neoadjuvant chemotherapy and HRD score as predictor of response - final results from GeparSixto. Ann Oncol 2018. doi:10.1093/annonc/mdy460

[73] Wardley AM, Hiller L, Howard HC et al. tAnGo: a randomised phase III trial of gemcitabine in paclitaxel-containing, epirubicin/cyclophosphamide-based, adjuvant chemotherapy for early breast cancer: a prospective pulmonary, cardiac and hepatic function evaluation. $\mathrm{Br}$ J Cancer 2008; 99: 597-603

[74] Swain SM, Tang G, Geyer CE jr. et al. Definitive results of a phase III adjuvant trial comparing three chemotherapy regimens in women with operable, node-positive breast cancer: the NSABP B-38 trial. J Clin Oncol 2013; 31: 3197-3204

[75] Earl HM, Vallier AL, Hiller L et al. Effects of the addition of gemcitabine, and paclitaxel-first sequencing, in neoadjuvant sequential epirubicin, cyclophosphamide, and paclitaxel for women with high-risk early breast cancer (Neo-tAnGo): an open-label, $2 \times 2$ factorial randomised phase 3 trial. Lancet Oncol 2014; 15: 201-212

[76] Bear HD, Tang G, Rastogi P et al. Bevacizumab added to neoadjuvant chemotherapy for breast cancer. N Engl J Med 2012; 366: 310-320

[77] Bear HD, Tang G, Rastogi P et al. Neoadjuvant plus adjuvant bevacizumab in early breast cancer (NSABP B-40 [NRG Oncology]): secondary outcomes of a phase 3, randomised controlled trial. Lancet Oncol 2015; 16: 1037-1048

[78] von Minckwitz G, Timms K, Untch M et al. Homologous repair deficiency (HRD) as measure to predict the effect of carboplatin on survival in the neoadjuvant phase II trial GeparSixto in triple-negative early breast cancer. Cancer Res 2017; 77: Abstr. P1-09-02

[79] Hahnen E, Lederer B, Hauke J et al. Germline Mutation Status, Pathological Complete Response, and Disease-Free Survival in Triple-Negative Breast Cancer: Secondary Analysis of the GeparSixto Randomized Clinical Trial. JAMA Oncol 2017; 3: 1378-1385

[80] Untch M, Jackisch C, Schneeweiss A et al. Nab-paclitaxel versus solventbased paclitaxel in neoadjuvant chemotherapy for early breast cancer (GeparSepto-GBG 69): a randomised, phase 3 trial. Lancet Oncol 2016; 17: 345-356

[81] Schneeweiss A, Jackisch C, Schmatloch S et al. Survival analysis of the prospectively randomized phase III GeparSepto trial comparing neoadjuvant chemotherapy with weekly nab-paclitaxel with solvent-based paclitaxel followed by anthracycline-cyclosphosphamide for patients with early breast cancer - GBG69 [abstract]. In: Proceedings of the 2017 San Antonio Breast Cancer Symposium; 2017 Dec 5-9; San Antonio, TX Philadelphia (PA): AACR. Cancer Res 2018; 78: Abstr. GS3-05

[82] Gluz O, Nitz U, Liedtke $C$ et al. Comparison of Neoadjuvant Nab-Paclitaxel+Carboplatin vs. Nab-Paclitaxel+Gemcitabine in Triple-Negative Breast Cancer: Randomized WSG-ADAPT-TN Trial Results. J Natl Cancer Inst 2018; 110: 628-637

[83] Gluz O, Nitz U, Liedtke C et al. Impact of 12 weeks nab-paclitaxel + carboplatin or gemcitabine followed by anthracycline administration according to PCR in triple-negative early breast cancer: Survival results of WSG-ADAPT-TN phase II trial. J Clin Oncol 2018; 36 (Suppl): Abstr. 573

[84] Gluz O, Nitz U, Liedtke $C$ et al. No survival benefit of chemotherapy escalation in patients with $p C R$ and high-immune triple-negative early breast cancer in the neoadjuvant WSG-ADAPT-TN trial. San Antonio Breast Cancer Symposium 2018; Abstr. GS5-06

[85] Cortazar P, Zhang L, Untch M et al. Pathological complete response and long-term clinical benefit in breast cancer: the CTNeoBC pooled analysis. Lancet 2014; 384: 164-172

[86] Sparano JA, Gray RJ, Makower DF et al. Adjuvant Chemotherapy Guided by a 21-Gene Expression Assay in Breast Cancer. N Engl J Med 2018; 379 : $111-121$ 
[87] Wagner LI, Gray RJ, Garcia S et al. Symptoms and health-related quality of life on endocrine therapy alone (E) versus chemoendocrine therapy $(\mathrm{C}+\mathrm{E})$ : TAlLORx patient-reported outcomes results. San Antonio Breast Cancer Symposium 2018; Abstr. GS6-03

[88] Janni W, Schneeweiss A, Müller V et al. Update Breast Cancer 2019 Part 2 - Implementation of Novel Diagnostics and Therapeutics in Advanced Breast Cancer Patients in Clinical Practice. Geburtsh Frauenheilk 2019; 268-280

[89] Early Breast Cancer Trialists' Collaborative Group. Effects of prolonging adjuvant aromatase inhibitor therapy beyond five years on recurrence and cause-specific mortality: An EBCTCG meta-analysis of individual patient data from 12 randomised trials including 24,912 women. San Antonio Breast Cancer Symposium 2018; Abstr. GS3-03

[90] Ohtani S, lijima K, Higaki K et al. A prospective randomized multi-center open-label phase III trial of extending aromatase-inhibitor adjuvant therapy to 10 years - Results from 1697 postmenopausal women in the N-SAS BC05 trial: Arimidex extended adjuvant randomized study (AERAS). San Antonio Breast Cancer Symposium 2018; Abstr. GS3-04

[91] Baselga ], Campone M, Piccart M et al. Everolimus in postmenopausal hormone-receptor-positive advanced breast cancer. N Engl J Med 2012; 366: 520-529

[92] Tesch H, Stoetzer O, Decker T et al. Efficacy and safety of everolimus plus exemestane in postmenopausal women with hormone receptor-positive, human epidermal growth factor receptor 2-negative locally advanced or metastatic breast cancer: Results of the single-arm, phase IIIB 4EVER trial. Int J Cancer 2019; 144: 877-885

[93] Dowsett M, Jacobs S, Johnston S et al. PALLET: A neoadjuvant study to compare the clinical and antiproliferative effects of letrozole with and without palbociclib. San Antonio Breast Cancer Symposium 2018; Abstr. GS3-02

[94] Hadji P, Blettner M, Harbeck N et al. The Patient's Anastrozole Compliance to Therapy (PACT) Program: a randomized, in-practice study on the impact of a standardized information program on persistence and compliance to adjuvant endocrine therapy in postmenopausal women with early breast cancer. Ann Oncol 2013; 24: 1505-1512

[95] Hadji P, Jackisch C, Bolten W et al. COMPliance and Arthralgia in Clinical Therapy: the COMPACT trial, assessing the incidence of arthralgia, and compliance within the first year of adjuvant anastrozole therapy. Ann Oncol 2014; 25: 372-377

[96] Hadji P, Ziller V, Kyvernitakis J et al. Persistence in patients with breast cancer treated with tamoxifen or aromatase inhibitors: a retrospective database analysis. Breast Cancer Res Treat 2013; 138: 185-191

[97] Nabieva N, Fehm T, Haberle L et al. Influence of side-effects on early therapy persistence with letrozole in post-menopausal patients with early breast cancer: Results of the prospective EvAluate-TM study. Eur J Cancer 2018; 96: 82-90
[98] Nabieva N, Kellner S, Fehm T et al. Influence of patient and tumor characteristics on early therapy persistence with letrozole in postmenopausal women with early breast cancer: results of the prospective Evaluate-TM study with 3941 patients. Ann Oncol 2018; 29: 186-192

[99] Fernandez-Gonzalez S, Falo C, Pla MJ et al. The Shift From Sentinel Lymph Node Biopsy Performed Either Before or After Neoadjuvant Systemic Therapy in the Clinical Negative Nodes of Breast Cancer Patients. Results, and the Advantages and Disadvantages of Both Procedures. Clin Breast Cancer 2018; 18: 71-77

[100] Fasching PA, Gass P, Hein A. Neoadjuvant Treatment of Breast Cancer Advances and Limitations. Breast Care (Basel) 2016; 11: 313-314

[101] Robertson JFR, Dowsett M, Bliss JM et al. Peri-operative Aromatase Inhibitor treatment in determining or predicting Longterm Outcome in Early Breast Cancer - the POETIC* Trial (CRUK/07/015) [abstract]. In: Proceedings of the 2017 San Antonio Breast Cancer Symposium; 2017 Dec 5-9; San Antonio, TX Philadelphia (PA): AACR. Cancer Res 2018; 78: Abstr. GS1-03

[102] Spring LM, Fell G, Arfe A et al. Pathological complete response after neoadjuvant chemotherapy and impact on breast cancer recurrence and mortality, stratified by breast cancer subtypes and adjuvant chemotherapy usage: Individual patient-level meta-analyses of over 27,000 patients. San Antonio Breast Cancer Symposium 2018; Abstr. GS2-03

[103] von Minckwitz G, Huang CS, Mano MS et al. Trastuzumab Emtansine for Residual Invasive HER2-Positive Breast Cancer. N Engl J Med 2018. doi:10.1056/NEJMoa1814017

[104] Geyer CE jr., Huang CS, Mano MS et al. Phase III study of trastuzumab emtansine (T-DM1) vs. trastuzumab as adjuvant therapy in patients with HER2-positive early breast cancer with residual invasive disease after neoadjuvant chemotherapy and HER2-targeted therapy including trastuzumab: Primary results from KATHERINE. San Antonio Breast Cancer Symposium 2018; Abstr. GS1-10

[105] Fasching PA, Hartkopf AD, Gass P et al. Efficacy of neoadjuvant pertuzumab in addition to chemotherapy and trastuzumab in routine clinical treatment of patients with primary breast cancer: a multicentric analysis. Breast Cancer Res Treat 2018. doi:10.1007/s10549-0185008-3

[106] Refae S, Pistilli B, Delaloge S. Extended anti-HER2 therapy in early breast cancer: longer beats shorter? Curr Opin Oncol 2016; 28: 469475

[107] Pivot X, Romieu G, Debled M et al. PHARE randomized trial final results comparing 6 to 12 months of trastuzumab in adjuvant early breast cancer. San Antonio Breast Cancer Symposium 2018; Abstr. GS2-07 